\title{
Revista de Historia Americana y Argentina
}

Vol. 56, № 1, 2021, Mendoza (Argentina) Facultad de Filosofía y Letras, Universidad Nacional de Cuyo

ISSN: 0556-5960, ISSNe 2314-1549, pp. 303-337

Licencia Creative Commons Atribución-NoComercial-Compartirlgual 4.0 Internacional

\section{Entre la valorización de la democracia y la connivencia con la dictadura: Partidos políticos en Corrientes durante la "Revolución Libertadora"}

\section{Between the valorization of democracy and the collusion with the dictatorship: \\ Political Parties in Corrientes during the 'Liberating Revolution'}

\author{
María del Mar Solís Carnicer \\ Consejo Nacional de Investigaciones Científicas y Técnicas/ \\ Universidad Nacional del Nordeste \\ Instituto de Investigaciones Geohistóricas \\ Chaco, Argentina \\ marimarsolis@yahoo.com.ar \\ Leandro Nahuel Castelo \\ Universidad Nacional del Nordeste \\ Instituto de Investigaciones Geohistóricas \\ Chaco, Argentina \\ leandronahuelcastelo@gmail.com
}

Cómo citar este artículo/ How to cite this article: Solís Carnicer, M. M. y Castelo, L. N. (2021). Entre la valorización de la democracia y la connivencia con la dictadura. Partidos políticos en Corrientes durante la "Revolución Libertadora". Revista de Historia Americana y Argentina, 56 (1), pp. 303-337. https://doi.org/10.48162/rev.44.009 


\title{
Resumen
}

En el presente artículo abordamos la experiencia de los partidos políticos antiperonistas en el gobierno de la autodenominada Revolución Libertadora en la provincia de Corrientes. A lo largo del mismo, buscaremos identificar el rol que asumieron en la Intervención Federal, sus dirigencias, estructuras y procesos de conflicto y fraccionamiento, ocurridos tanto a nivel intra como extrapartidario. En el trabajo convergen herramientas teóricas y metodológicas provenientes de la Historia Política y del enfoque regional, con la intención de contribuir a las diferentes interpretaciones sobre la política del periodo desde una mirada provincial. Nos centramos en el análisis de la prensa escrita local, particularmente los diarios El Liberal y La Mañana, y de otros documentos como los decretos de la Intervención, informes de gobierno, correspondencia -personal y oficial- y el testimonio oral de uno de sus actores.

En el escenario abierto tras el golpe de Estado, el retorno a la actividad política estuvo atravesado por un proceso de reorganización general en los partidos que, en ocasiones, generó crisis y fraccionamientos. Las reconfiguraciones identitarias y la adaptación de los programas a la nueva realidad, los encontró en un constante tránsito entre la defensa de valores democráticos y el acompañamiento al gobierno militar.

Palabras clave: partidos políticos; Corrientes; revolución libertadora.

\begin{abstract}
In this article we discuss the experience of antiperonist political parties in the government of the self-proclaimed Liberating Revolution in Corrientes province. Throughout it, we seek to identify the role they assumed in the Federal Intervention, their leaderships, structures and processes of conflict and division, which occurred both within themselves and extra-party level. The work applies theoretical and methodological tools from Political History and the regional approach, with the intention of contributing to the different interpretations of the politics of the period from a provincial perspective. We focus on the analysis of the local written press, specifically the newspapers El Liberal and La Mañana, and other documents such as the Intervention decrees, government reports, correspondence - personal and official - and the oral testimony of one of its actors.

In the open scenario after the military coup, the return to political activity was intertwine by a process of general reorganization in the parties that, occasionally, generated crisis and divisions. The identity reconfigurations and the adaptation of the programs to the new reality derived in a constant transition between the defense of democratic values and the support for the military government.
\end{abstract}

Key words: political parties; Corrientes; liberating revolution.

Recibido: 26/07/2020 Aceptado: 21/12/2020 


\section{Introducción}

A mediados de septiembre de 1955, una serie de levantamientos armados planificados en distintos puntos del país concluyeron con el golpe de Estado que dio clausura a una década de gobierno peronista. Encabezadas por sectores militares, las sublevaciones contaron con el apoyo de importantes grupos civiles y político partidarios (Spinelli, 2005). Esta situación, con algunas variantes, se extendería durante los dieciocho meses que duró la autodenominada Revolución Libertadora, lo que habilita a interpretarla como una auténtica dictadura cívico-militar (Ansaldi, 2014). En este sentido, uno de los elementos propios de la etapa fue el carácter institucional que adquirió la participación de los partidos políticos en la Junta Consultiva Nacional y las juntas homólogas provinciales, así como la incorporación de sus representantes en otros espacios de poder.

En el presente artículo, buscaremos aportar al conocimiento del papel que asumieron los partidos políticos durante el gobierno de la libertadora a partir de un análisis enfocado en la política correntina. A lo largo del mismo, nos proponemos identificar su rol en la Intervención Federal que actuó en la provincia entre septiembre de 1955 y marzo de 1958, a la vez que reconocer sus dirigencias, estructuras y procesos de conflicto y fraccionamiento -tanto a nivel intra como extrapartidario- con el objetivo de echar luz sobre algunos aspectos peculiares que ofrece este caso y que permiten complejizar las interpretaciones más generales que se construyeron sobre esta etapa. Nos enfocaremos en la experiencia de cuatro sectores en particular, la UCR, el Partido Demócrata Autonomista $(P D A)^{1}$, el Partido Liberal (PL) y el Partido Demócrata Cristiano (PDC), protagonistas en el proceso de transición que desembocaría en el triunfo frondizista de 1958.

Cabe destacar que, en contraste con el volumen de investigaciones históricas concentradas en el estudio del primer peronismo, la etapa posterior al derrocamiento de Perón no ha recibido la misma atención. Un repaso por las interpretaciones iniciales deja entrever que las mismas provienen de la Sociología y la Ciencia Política y encuentran en este momento el punto de partida para explicar los vaivenes de la política

\footnotetext{
${ }^{1}$ Alineado al Partido Demócrata Nacional.
} 
argentina en la segunda mitad del siglo $X X^{2}$. Estas variables aportaron al conocimiento de la lógica interna del proceso de inestabilidad y fracaso de la democracia hasta la década de 1980 pero no prestaron atención al papel jugado por los individuos, las razones esgrimidas por los actores, sus imaginarios $o$ el sustrato de sus ideas y sentimientos. Tales cuestiones empezarían a ser cubiertas por la historiografía, especialmente a partir de los trabajos de Estela Spinelli (2005), Julio Melón Pirro (2009) y César Tcach $(2012)^{3}$. Más recientemente, se han publicado estudios que analizan el proceso desde otras perspectivas y escalas. Consideramos aquí aquellos que lo retoman desde la política de desperonización, el antiperonismo o instituciones como las juntas consultivas y las comisiones investigadoras e inclusive aquellos que priorizan una perspectiva regional, cuestiones hasta hace algunos años escasamente abordadas de manera sistemática ${ }^{4}$.

${ }^{2}$ Concebida como el período que podía explicar el largo proceso de inestabilidad política en la Argentina de la segunda mitad del siglo XX, importantes sociólogos y politólogos ensayaron diferentes esquemas teóricos tratando de pensar los dilemas generados por la Revolución Libertadora. Guillermo O’Donnell (1972) calificó a la etapa como "un juego imposible" dadas las dificultades de ganar elecciones sin contar con el voto peronista y de conservarse en el gobierno sin el apoyo del Ejército que proscribía al peronismo; Catalina Smulovitz (1991), señaló -a diferencia de O'Donnell- que en realidad los partidos jugaban "juegos múltiples y yuxtapuestos" y la cuestión fundamental que se plantearon resolver fue la "cuestión peronista"; Marcelo Cavarozzi (1983) identificó a la etapa como una "semidemocracia" por estar el peronismo proscripto; José Nun (1973) utilizó la metáfora del "parlamentarismo negro" por el ejercicio de la política fuera de los canales institucionales y Juan Carlos Portantiero (1973) utilizó la idea de "empate hegemónico" porque cada uno de los actores tenía capacidad para bloquear los proyectos de sus adversarios pero era incapaz de realizar los propios.

${ }^{3}$ Citamos aquí únicamente los libros publicados por estos autores, pero dejamos constancia de que todos ellos cuentan con un importante número de artículos sobre la temática.

${ }^{4}$ Merecen citarse aquí el pionero trabajo de César Tcach (1994, pp. 17-30) y el dossier que se publicó en la revista Entornos con motivo de cumplirse los 40 años del derrocamiento de Perón, en el que participaron entre otros Ricardo Sidicaro, Lucio Garzón Maceda y Luis Alberto Romero. Paralelamente, desde diferentes provincias, en los últimos años se dio un nuevo impulso a los trabajos sobre el período. En este sentido es importante citar el Dossier publicado en el $N^{\circ} 16$ de la revista Páginas de la Escuela de Historia de la Universidad de Rosario, del año 2016 coordinado por Fernando Aníbal Castillo que reúne trabajos de Yamile Álvarez, Silvana Ferreyra, Leandro Lichtmajer, Marta Ruffini y del mismo compilador que 
Para el desarrollo de este trabajo, nos hemos centrado en la prensa periódica local, en particular los diarios El Liberal (EL) y La Mañana (LM), que por sus características posibilitan un acercamiento privilegiado a los acontecimientos. El primero, una reconocida voz oficialista durante el peronismo, mostró su apoyo a la nueva gestión, no sin que mediaran presiones oficiales. El segundo, propiedad de Elías Abad, político autonomista, fue un canal de expresión de ese sector y canalizó muchas de las críticas al gobierno. Añadimos al análisis los decretos de la Intervención Federal ubicados en el Archivo General de la Provincia de Corrientes (AGPC), los expedientes e informes de la Comisión Investigadora de la provincia y de la propia intervención, resguardados en el Archivo General de la Nación (DAI-AGN), la correspondencia -oficial y personal- junto a otros documentos del Fondo Isaac Rojas perteneciente al Departamento de Estudios Históricos Navales (DEHN) y el testimonio oral de Ricardo Leconte, dirigente político que presidió la Juventud del Partido Liberal en este período y fue diputado provincial electo en los comicios que marcaron el retorno democrático.

\section{Los partidos políticos en la intervención federal}

En sus inicios, la Revolución Libertadora estuvo presidida por el general Eduardo Lonardi, quien asumió el mando después de la renuncia de Juan Domingo Perón. Sin embargo, su política moderada con respecto al peronismo, sintetizada en la frase "ni vencedores, ni vencidos", y su resistencia a la injerencia de los partidos políticos en el gobierno motivaron inmediatamente las críticas por parte de los sectores más antiperonistas. En una postura más radicalizada y revanchista hacia el movimiento derrocado, a la vez que abierto a la inclusión político partidaria, se encontraba el vicepresidente Isaac Rojas, quien impulsó la creación de la Junta Consultiva para integrar a las fuerzas opositoras al peronismo (con excepción del Partido Comunista) en un organismo asesor del gobierno nacional. Tras una serie de sucesos, las tensiones en el seno del poder central derivaron en la destitución del presidente y la asunción del general Pedro Eugenio Aramburu. El cambio en el mando acarrearía el alejamiento definitivo de los cuadros que habían visto la posibilidad de retomar algunos postulados del peronismo considerados positivos, sobre todo en lo relacionado a la

abordan los casos de Mendoza, Buenos Aires, Tucumán, Río Negro y Jujuy respectivamente, también Valobra (2013). 
organización y el disciplinamiento de la clase obrera y los sindicatos (Spinelli, 2005).

Por otro lado, el viraje en el gobierno de Aramburu estuvo dado por una profundización en la política de desperonización. En este punto, desmontar el aparato peronista no se limitó solamente a la faceta investigadora y represiva desplegada sobre el movimiento, sino que estuvo acompañada por diversas medidas que pretendían devolver la autonomía institucional al país y derogar la legislación que el régimen había utilizado contra sus opositores, allanando así, el camino para el retorno al orden democrático (Ferreyra, 2018). Entre las acciones más relevantes estuvieron la disolución de la Fundación Eva Perón, la intervención de sindicatos y de la CGT, la reasignación de nombres ligados al peronismo de numerosos espacios públicos, la inhabilitación para desempeñar cargos públicos a ex funcionarios peronistas, la prohibición del uso de símbolos, emblemas, fotografías, vinculadas al movimiento y la propia proscripción del partido ${ }^{5}$ El objetivo era erradicar la identidad de una fuerza política con amplias bases de apoyo y, para ello, fue fundamental la labor de las comisiones investigadoras en todo el territorio, desde donde se rastrearon posibles irregularidades y delitos llevados a cabo en la gestión depuesta.

En lo que respecta a la administración de los espacios provinciales, el gobierno provisional hizo uso de las intervenciones federales. En Corrientes, a los pocos días de producido el golpe, se hizo cargo de dicha función el general Esteban Font ${ }^{6}$, un hombre del Ejército con experiencia en el ámbito local debido a que comandaba una división militar en la provincia. Este sería sucedido días después, también en forma interina, por el coronel Oscar Dumas. Para algunos sectores, la presencia de Font implicó un retraso en la llegada de la Revolución. Se trataba pues, de quien había tenido a su cargo la represión del levantamiento en Curuzú Cuatiá y además, habría garantizado la huida del gobernador depuesto, Raúl Castillo, hacia la frontera brasileña ${ }^{7}$. De todas maneras, la gestión de estos primeros interventores fue breve y para principios de octubre tomó posesión del cargo

${ }^{5}$ El Decreto $N^{\circ} 4161 / 56$ sancionado durante el gobierno del General Aramburu estableció muchas de las medidas aquí mencionadas.

${ }^{6}$ Esta mañana a las 12.30 asumió el gobierno de la provincia el Comandante Divisionario General Font. Archivo General de la Provincia de Corrientes (en adelante AGPC), Diario El Liberal (EL), Corrientes, 21-9-1955, p. 1.

${ }^{7}$ AGPC, Diario La Mañana (LM), Corrientes, 9-11- 1955, p. 1. 
quien sería el titular definitivo. Podemos interpretar que el primer recambio estuvo motivado por el imperativo de contar con una figura alineada a los principios revolucionarios de modo inmediato, algo que Dumas supo representar. A pesar de un mandato efímero, los numerosos decretos emitidos demuestran la puesta en marcha de un proceso de reorganización de la administración estatal, lo que incluyó desde cesantías a trabajadores hasta el restablecimiento de los nombres de algunas calles de la ciudad ${ }^{8}$. En esta primera etapa, la composición del personal político en los espacios estratégicos -ministerios, secretarías, jefatura de policía, municipalidad capital- tuvo como nota predominante la designación de figuras militares (sobre todo del ejército).

El 3 de octubre asumió sus funciones de interventor el capitán de navío Manuel Bianchi $^{9}$, quien se mantuvo en ese cargo hasta el retorno institucional en 1958. Esta cuestión marca una primera diferencia con lo sucedido en el ámbito nacional, puesto que las tensiones del orden presidencial no se reprodujeron en la provincia. Los sucesos en Corrientes demuestran que con la llegada del mandatario se produjo un nuevo recambio de funcionarios en las primeras líneas ministeriales, secretarías generales, privadas y técnicas, donde el elemento significativo se dio por la incorporación de figuras de la marina y un número cada vez más elevado de civiles, fundamentalmente a partir de las segundas y terceras líneas (a excepción del Ministerio de Economía, donde predominaron hombres del ámbito civil). Por otro lado, el gobierno de Bianchi estuvo orientado desde los inicios a establecer un diálogo con los distintos partidos políticos locales. Con el objetivo de contar con su asesoramiento, al poco tiempo de asumir, convocó reuniones y llevó adelante entrevistas con dirigentes de las principales fuerzas. Para este momento, los sectores antiperonistas que gravitaban eran el PDA, el PL, el PDC, la UCR, el radicalismo antipersonalista (UCRA), los demócratas progresistas (PDP) y, con menor injerencia, comunistas (PC) y socialistas (PS). A pesar de que la mayoría demostró una expresa adhesión a la causa libertadora, la distribución de los cargos y las exclusiones nos permiten comprender algunas dinámicas.

En línea con los propósitos nacionales, en el mes de octubre se creó la Comisión Investigadora local. La misma estuvo conformada por una comisión central y veintiocho subcomisiones, de las cuales, diez estaban

\footnotetext{
${ }^{8} E L, 23-9-1955$, p. 1.

${ }^{9}$ AGPC, Secretaria de la Gobernación (SG), Año 1955, Tomo 16, Decreto №118.
} 
orientadas a casos especiales y las restantes se fueron abriendo en distintos departamentos del interior provincial. La composición del organismo fue resultado de las negociaciones de Bianchi con las distintas fuerzas políticas, método que se repetiría en otras estructuras. La comisión central, por ejemplo, contó con nueve miembros al momento de su creación y en ella, a excepción del mayor Alfredo Vara -que la presidió por unos días- se desempeñaron referentes partidarios locales (ver cuadro $\mathrm{n}^{0} \mathbf{1}$ ).

Cuadro n 1: Comisión Provincial de Investigaciones. Comisión Central, 1955

\begin{tabular}{|l|c|c|}
\hline \multicolumn{3}{|c|}{ COMISIÓN INVESTIGADORA PROVINCIAL } \\
\hline \multicolumn{3}{|c|}{ COMISIÓN CENTRAL } \\
\hline Nombre y Apellido & Afiliación & Cargo \\
\hline Alfredo Vara* & Ejército & Presidente \\
\hline Roberto A. Billinghurst** & UCR & Presidente \\
\hline Alberto V. Gutnisky & UCR & Presidente \\
\hline César Arballo & UCR & Secretario \\
\hline Pedro G. de la Fuente & PDA & Miembro de Comisión \\
\hline Pedro B. de la Vega & UCR & Miembro de Comisión \\
\hline José Jorge Contte & PL & Miembro de Comisión \\
\hline Luis T. Mansutti & $s / d$ & Miembro de Comisión \\
\hline Juan Mauricio Bruzera & $s / d$ & Miembro de Comisión \\
\hline Laureano Luis Ortiz & $s / d$ & Miembro de Comisión \\
\hline $\begin{array}{l}{ }^{*} \text { Renuncia el 24 de octubre de 1955. } \\
\text { **Renuncia el 22 de febrero y asume Gutnsky. }\end{array}$ \\
\hline
\end{tabular}

Fuente: Elaboración propia a partir de datos obtenidos del Archivo General de la Nación, Departamento de Archivo Intermedio, Fondo de la Fiscalía de Recuperación Patrimonial.

Cabe resaltar que estas comisiones se consolidaron como espacios de poder y las diferentes fuerzas tuvieron en cuenta esta cuestión. Otro organismo que siguió una lógica similar fue la Junta Provincial de Recuperación Patrimonial, donde se destacó la presencia del PDA, del PL y la UCR. Las comisiones investigadoras funcionaron entre octubre de 1955 y 
abril de 1956, cuando por orden del gobierno provisional fueron terminadas sus actividades y elevados los informes de los trabajos realizados. Posteriormente, estos últimos fueron recopilados y editados en diversas publicaciones que sirvieron como instrumento de difusión sobre los actos de corrupción llevados a cabo por el gobierno peronista.

En lo que respecta a la Junta Consultiva, no será hasta enero del año siguiente cuando Bianchi firme el decreto de su creación, señalando entre los considerandos que era "conveniente para la orientación de los problemas de Estado la institución (...) de un órgano similar al establecido por el gobierno de la Nación, con el objeto de prestarle su asesoramiento en los problemas y actividades de toda índole"10. La junta local se constituyó con veinte miembros que representaron al PDA, PL, PDP, UCRA y al recientemente creado PDC (ver cuadro $n^{\circ} 2$ 2). Los funcionarios contaron con fueros similares a los de un legislador en tiempos democráticos y se encargaron de tratar temas solicitados por el Ministerio de Gobierno de la Intervención. Al igual que en otras provincias, como el caso de Río Negro (Ruffini, 2016b), resulta llamativa la ausencia de representantes del radicalismo alineado al Comité Nacional presidido por Arturo Frondizi, que sí integraba la Junta Nacional y que contaba con el caudal mayoritario de votos en la provincia si tomamos como referencia las últimas elecciones del período peronista. Por otro lado, el hecho de que hayan estado como consultivos los representantes del antipersonalismo, un partido prácticamente desaparecido de la escena política nacional y provincial, motiva un análisis que considere las posibles tensiones y conflictos que se habían planteado entre la UCR y el gobierno por los cargos públicos.

${ }^{10}$ EI P. E. creó la Junta Consultiva Provincial. EL, 11-1-1956, p. 1. 
Cuadro N²: Junta Consultiva de la Provincia de Corrientes (1956-1957)

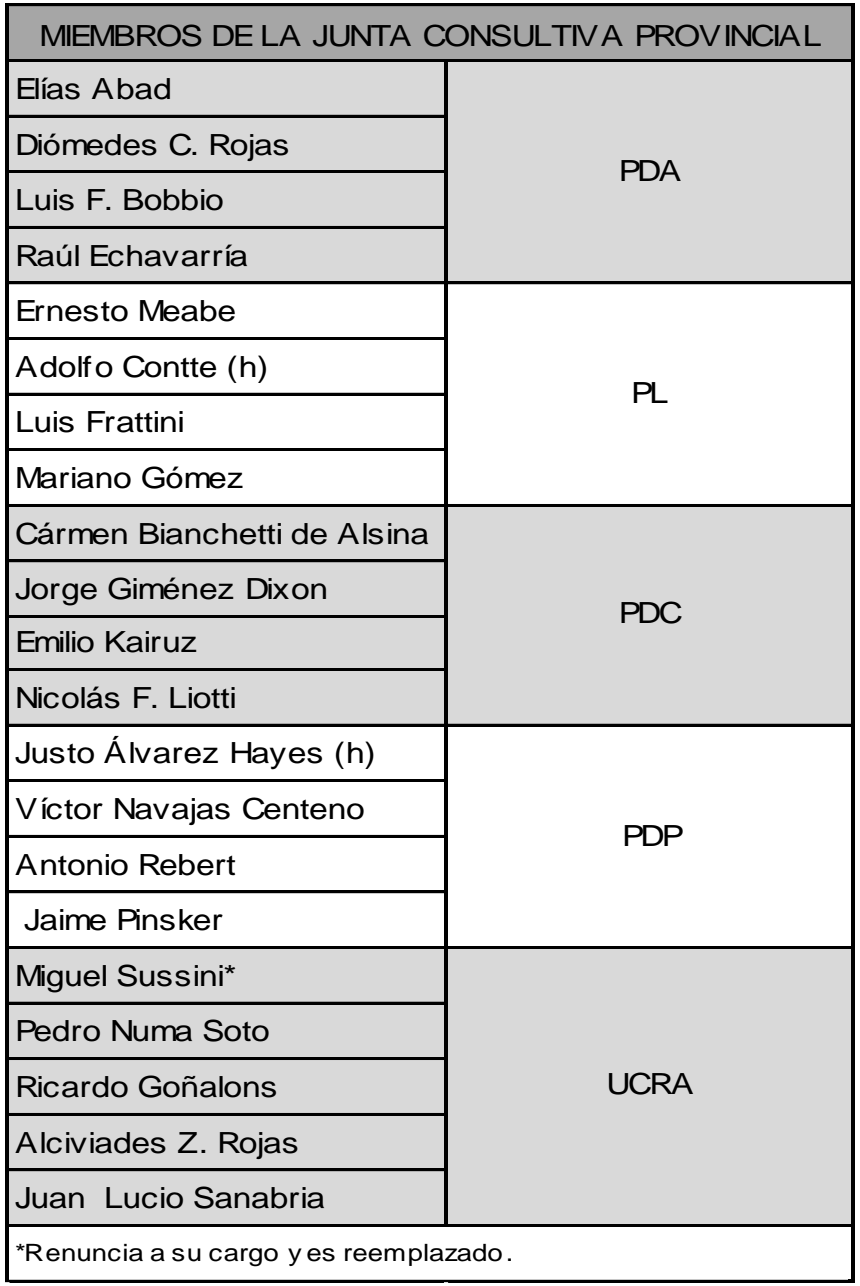

Fuente: Elaboración propia a partir de datos del Decreto 6/1956 (AGPC).

Silvana Ferreyra (2016) señala que la Junta Nacional estuvo encargada de tratar tópicos de importancia, como la discusión sobre la reforma constitucional, los informes económicos presentados por Raúl Prebisch, la explotación de los recursos estratégicos o el pedido de préstamos a 
entidades financieras externas. Ya que no contamos con las actas de la junta provincial, el análisis sobre la relevancia del organismo en la política local se limita al seguimiento de la prensa donde, de hecho, destacan algunas notas referidas a su escasa intervención en temas significativos. Un artículo de EL publicado en septiembre de 1956, al calor de los debates sobre la modificación de la constitución, menciona que las sesiones, que debían a llevarse a cabo por órdenes del ejecutivo nacional en todas las jurisdicciones, se frustraban por la falta de quórum ${ }^{11}$. Es necesario considerar que los itinerarios del escenario local condicionaron la actividad, ya que su funcionamiento efectivo se restringe al período existente entre febrero de 1956 y marzo de 1957, cuando una serie de eventos políticos que implicaron destituciones y renuncias de la mayoría de los miembros, sentenciaron su final. También debemos tener en cuenta que la injerencia político partidaria en el gobierno no se terminaba en las reuniones de la junta dado que, como hemos mencionado, esta se extendía a su participación en otros cargos de la administración local y a las constantes comunicaciones con el interventor.

Resulta lógico que los sucesos en Corrientes presenten particularidades propias, no obstante, los eventos del orden nacional delimitaron en diversas ocasiones los temas de debate y el clima político. A partir de estas consideraciones podemos concebir dos grandes momentos que atraviesan los partidos durante la Revolución Libertadora. El primero inicia con el establecimiento del gobierno provisional en septiembre de 1955 y está caracterizado por la vuelta al escenario político de la mayoría de las fuerzas, que luego de superar una etapa de poco protagonismo dan comienzo a una reorganización general mediante la designación de nuevas autoridades, redefinición de programas, cartas orgánicas y principios. La misma se extiende hasta fines de 1956, en el marco de las tensiones al interior del autonomismo y del radicalismo que derivaron en su fraccionamiento. La segunda etapa comprende el último año y medio del gobierno revolucionario, donde la coyuntura política está atravesada por los realineamientos partidarios en las dos fuerzas que sufrieron divisiones (UCR y PDA), el debate en torno a la Convención Constituyente -donde los temas son diversos- y los comicios generales que, si por un lado marcaron el retorno a la normalidad institucional, por el otro, implicaron disputas por las candidaturas y el enfrentamiento entre los distintos actores.

${ }^{11} E L, 20-9-1956$, p. 8. 


\section{Reorganización partidaria y tensiones (1955-1956)}

La Revolución Libertadora implicó para la mayoría de los partidos antiperonistas una vuelta al escenario del que habían perdido protagonismo. En el contexto local, previo al derrocamiento de Perón, la UCR había sido el único partido de oposición con representación parlamentaria ${ }^{12}$, el PDA había reducido drásticamente su electorado y el PL se había abstenido de participar en elecciones desde 1947. No obstante, el retorno no se limitó a estos tres sectores. La UCR Antipersonalista, que contaba con algunos simpatizantes, intentó reorganizarse luego del golpe y el PDC, constituido en octubre de 1955, hizo lo propio con la revolución ya en marcha. A ellos se sumaban el PDP, el PS y el PC, aunque con escasa relevancia electoral. $\mathrm{Si}$ bien todos se manifestaron a favor del nuevo gobierno y sus comunicados públicos fueron difundidos por la prensa, pronto empezaron a plantearse cuestionamientos hacia algunas medidas de la Intervención, a la vez que las tensiones intra y extrapartidarias se hicieron evidentes.

En lo que respecta al orden intrapartidario, fue justamente en el nuevo panorama atravesado por la reestructuración -con reuniones, búsqueda de adhesiones, elección de autoridades y aperturas de comités y subcomités en los distritos de la provincia- donde detonaron los conflictos que más adelante derivarían en rupturas y hasta en reposicionamientos ideológicos. Las experiencias del radicalismo y el autonomismo son esclarecedoras y grafican el clima político imperante. El primero de ellos arribó al escenario post septiembre con una realidad partidaria similar a la del resto del país, esto es, con divisiones en su interior. Los conflictos previos en torno a la dirección del Comité Nacional y las disputas por los espacios jerárquicos se profundizaron tras el derrocamiento del peronismo (Lichtmajer, 2016). Solamente en el Movimiento de Intransigencia y Renovación (MIR), que era el sector mayoritario alineado a Frondizi, se identificaban tres fracciones: una línea del comité central provincial, encabezada por Fernando Piragine Niveyro, el bloque Hipólito Yrigoyen y el Movimiento Leandro N. Alem. Un segundo grupo fue el Movimiento de Intransigencia y Renovación Argentinista (MIRA), ubicado detrás de la figura del cordobés Amadeo Sabattini, líder del Movimiento Intransigencia Nacional (MIN), con Desiderio

\footnotetext{
${ }^{12}$ En las elecciones legislativas de 1951, la UCR obtuvo el $26,4 \%$ de los votos, frente al $65 \%$ logrado por el peronismo. Con estos resultados, los radicales obtuvieron once diputados y cuatro senadores en el Congreso provincial, y los peronistas, por su parte, veinticinco diputados y catorce senadores. Véase Solís Carnicer (2017).
} 
Dante como referente provincial. Por último, un sector crítico del ala frondizista y cercano al unionismo, estuvo representado por Roberto Billinghurst y Jorge Benchetrit Medina como principales actores.

Los comicios para elegir autoridades partidarias se llevaron a cabo en todo el país entre fines de 1955 y principios de 1956. A excepción de Catamarca y Salta, donde no se realizaron las elecciones, Mendoza, donde ganó el unionismo y las provincias de Santiago del Estero y Córdoba, donde triunfó el sabattinismo, el frondizismo se alzó con la victoria en todos los distritos (Persello, 2007). Hacia noviembre, en el marco local, el partido había acordado la presentación de una lista única tanto para el comité de la capital -con Niveyro de presidente- como para las autoridades departamentales. La competencia, entonces, se daría por los cargos nacionales (delegados al comité y la convención) con tres propuestas: una lista del MIR, una disidente (unionistas) y otra del MIRA ${ }^{13}$. Sin embargo, este último sector decidió abstenerse en disconformidad con las autoridades partidarias. Por esos días, el movimiento publicó una declaración donde denunciaban la negativa de posponer las elecciones hasta diciembre, algo que habían solicitado con el objetivo de poder organizarse y reprochaban la actitud de la dirigencia, que aceptó correr las fechas nada más que por una semana, dando por finalizado el período de oficialización de listas e impidiendo su participación ${ }^{14}$. Más allá de los reclamos, el posterior triunfo del MIR fue abrumador (5786 votos contra 326$)^{15}$.

Esta situación, que no fue exclusiva de la política correntina, marcaría uno de los tantos desencuentros entre frondizistas y sabattinistas que, a finales de 1956, luego de la Convención Nacional del partido en Tucumán, se abrirían y formarían la UCR del Pueblo junto a otras vertientes (unionistas y balbinistas). Según Leandro Lichtmajer (2016) este fraccionalismo presente en las filas radicales obedece a una combinación de factores instrumentales y programáticos, donde las pujas por los espacios de poder fueron determinantes.

Los demócratas autonomistas, alineados al Partido Demócrata Nacional presidido por Oscar Rebaudi Basavilbaso, también emergieron con divisiones en la escena libertadora. Durante la etapa peronista, un sector se

\footnotetext{
${ }^{13} L M, 26-11-1955$, p. 4.

${ }^{14} L M, 27-11-1955$, p. 1.

${ }^{15} E L, 28-11-1955$, p. 2.
} 
había consolidado bajo el liderazgo de Elías Abad, que se mantuvo como opositor al oficialismo. Otra línea, denominada Movimiento Libertad (ML), optó por la abstención electoral, aunque manteniéndose dentro de la organización. En esta etapa, la influencia del partido fue decreciendo, tanto por la pérdida de votos como por el acceso, cada vez más obstruido, a la participación parlamentaria. El retorno a la actividad política evidenció la necesidad de una reorganización y los meses posteriores al golpe estuvieron encarados por autoridades interinas que propiciaron la unidad, logrando el retorno del movimiento abstencionista. A mediados de 1956, se llevaron a cabo las elecciones de la junta de gobierno que consagraron a la lista de Abad en la presidencia. No obstante, meses después, tomaron estado público las diferencias con las nuevas autoridades, en este caso, debido a la sospecha de algunos sectores por el acercamiento del presidente al conservador bonaerense Vicente Solano Lima, luego de que este planteara una postura crítica hacia el revanchismo adoptado por la Junta Nacional y decidiera abrirse de la dirección de Basavilbaso.

En este escenario, Abad mantuvo su posición y expresó la adhesión del distrito a la nueva línea partidaria, algo que fue duramente cuestionado por parte de otros dirigentes locales. A partir de allí la fragmentación avanzó con velocidad y una parte de la junta lo acusó de no consultar la decisión tomada, contradiciendo el protocolo establecido en la carta orgánica partidaria. A la renuncia inmediata del dirigente Diomedes Rojas le siguieron la de otros miembros de relevancia que argumentaron su rechazo a las "maniobras antidemocráticas" y al "personalismo". Uno de los conceptos más recurrentes en las cartas de renuncia fue el de las "tendencias totalitarias" que no tenían asidero en los "nuevos tiempos". Si bien esta crisis intrapartidaria tenía un aparente origen en el ámbito nacional (la posición del partido frente a la cuestión peronista y la política revanchista), las repercusiones locales revivieron antecedentes propios que reflotaron las diferencias existentes entre Abad y Rojas desde principios de la década de 1940. El conflicto derivó en la intervención del distrito Corrientes por parte de la Junta Nacional y, posteriormente, el sector liderado por Abad conformó la expresión local del nuevo Partido Demócrata Conservador Popular (PDCP). Rojas, por su parte, quedó al frente del bloque que se mantuvo como PDA.

Las diferencias con la Intervención Federal también empezaron a ser visibles. Una de las primeras situaciones se dio en octubre -aunque se extendería hasta avanzado 1956-, cuando bajo el lema de la "prescindencia 
política" la Jefatura de Policía emitió una orden que instaba al personal a "abstenerse de toda actividad" partidaria. Desde la perspectiva del gobierno, los principales cargos en la fuerza policial constituían un factor determinante en el orden político. No obstante, la medida encontró una fuerte resistencia en la UCR, que contaba con un número elevado de comisarios afiliados. Como consecuencia, se sucedieron un sinfín de cruces que tomaron estado público, en donde el radicalismo reclamaba por la libertad como valor de la Revolución y el gobierno acusaba a éstos de querer mantener privilegios. Una instancia crucial se dio en febrero de 1956, cuando el Ministerio de Gobierno emitió una resolución que obligaba a los funcionarios policiales a renunciar a su afiliación partidaria ${ }^{16}$. Los argumentos se mantenían en la misma línea y recaían en la necesidad de dar "independencia al personal" y de "quitar el interés proselitista". Ante ello, desde la UCR se publicó un comunicado donde manifestaron su disconformidad y mencionaron la posibilidad de avanzar con medidas legales si "los empleados o funcionarios públicos que no se desafilien y no renuncien, fueran declarados cesantes" ${ }^{17}$.

Este intercambio entre el gobierno y el partido no era nuevo, de hecho, ya había tenido efectos en la política local; tiempo después un informe elevado por Bianchi al Ministerio del Interior, relataba una "campaña del radicalismo" que inició contra la Jefatura de Policía y que culminó con la negativa de enviar sus representantes a la Junta Consultiva Provincial ${ }^{18}$. En el mismo escrito, a su vez, se aclaraba que la confrontación se diluyó con la reconsideración del tema por parte del poder ejecutivo, que estableció nuevas medidas donde ya no existía la obligación de renunciar a la afiliación ni a los cargos, aunque establecía penalidades severas contra el proselitismo. A propósito de esta situación, cabe decir que las disputas entre los diferentes partidos implicaron numerosas demandas a la Intervención por la falta de prescindencia política $y$, en los reclamos, recayeron la totalidad de las fuerzas. Por el lado del gobierno, ello fue interpretado como prueba del equilibrio logrado por la administración, no obstante, también demuestra el clima agitado en el que se desenvolvió la competencia política.

\footnotetext{
${ }^{16} E L, 23-2-1956$, p. 1.

${ }^{17}$ Réplica de la UCR a una circular del Ministerio de Gobierno de Corrientes. EL, 272-1956, p. 2.

${ }^{18}$ Archivo General de la Nación (AGN) Departamento de Archivo Intermedio (DAI), Fondo del Ministerio del Interior (MI), Documentos Secretos, Confidenciales y Reservados (SCR), Caja (C) 134, Informe sobre prescindencia política.
} 
Otro testimonio de las tensiones entre el gobierno y los partidos quedó plasmado cuando Benchetrit Medina, columnista del diario La Mañana y representante del radicalismo, publicó una editorial donde criticó duramente la lentitud con que la Intervención había abordado la política de desperonización. Además, cuestionó el alcance de la Revolución y manifestó su descontento con los pocos cambios observados en la provincia. Si bien jamás negó el apoyo a la causa libertadora, no dudó en denunciar los magros avances en la reestructuración general:

A casi dos meses de la Revolución, en la mayoría de las oficinas importantes de la administración, aún en las antesalas de los propios ministros, casi nada ha cambiado. No se trata simplemente de las personas, de las caras de antes que siguen siendo las mismas caras de hoy; se trata de los procedimientos. Todo el armazón fiscalista y administrativo del peronismo sigue en pie. Casi todos los puestos llaves de la Administración (...) el interior de la provincia, fuera de los cargos de comisario e intendente, y alguno que otro de jerarquía, (...) las reparticiones nacionales de diversa índole, algunas de fundamental importancia en este lugar fronterizo, siguen dirigidas por las mismas manos del peronismo. Nada, casi nada, ha cambiado; la Revolución casi ni se advierte en ciertos lugares. Esto no puede ser. La Revolución no puede limitarse a bajar cuadros y a romper bustos. (...) No se trata simplemente de cambiar algunas figuras; hay que cambiar al sistema. Y para ello, debe deshacerse, hasta el último tornillo, la máquina del peronismo. (...) La Revolución está en Corrientes, pero no está del todo. Hay Revolución, pero poca ${ }^{19}$.

Desde el autonomismo también se replicaron las críticas y Elías Abad fue uno de los dirigentes que más confrontó con las autoridades de la Intervención y con el propio Bianchi. El diario La Mañana fue el canal privilegiado para difundir sus opiniones y, justamente, un artículo allí publicado a fines de 1956 fue el desencadenante de un enfrentamiento entre el político y el mandatario provincial. En aquella nota, Abad denunciaba un procedimiento arbitrario en donde la policía de la ciudad de Paso de los Libres había cometido abuso de autoridad y reprimido a un grupo de personas, por lo que responsabilizaba directamente a la gestión. Frente a esa situación, el gobierno acusó al dirigente de injuriar a las autoridades y la justicia lo imputó por calumnias ${ }^{20}$. Amparándose en sus

\footnotetext{
19Job. "Revolución, pero poca". LM, 9-11-1955, p. 1.

${ }^{20} E L, 28-2-1957$, p. 2.
} 
fueros como miembro consultivo, las sucesivas inasistencias de Abad a las mediaciones dictadas por el juez de la causa fueron consideradas como una falta del dirigente autonomista, que en la interpretación de Bianchi justificaron la decisión de desafectarlo de la Junta en febrero de 1957. La contienda tuvo un fuerte intercambio epistolar que se publicó en la prensa, y como consecuencia, los partidarios de Abad que estaban en la Junta, decidieron presentar su renuncia en solidaridad.

\section{Redefiniciones identitarias y la "cuestión peronista"}

Con la apertura de un escenario político renovado, tuvo lugar un proceso que afectó de manera generalizada a los distintos partidos antiperonistas y donde las reconfiguraciones identitarias y de los programas partidarios fueron factores determinantes. Estas cuestiones estuvieron cubiertas en gran parte por la radio y la prensa escrita, desde donde los dirigentes políticos supieron expresar en nombre de su partido, las diferentes posturas frente a la coyuntura y sus proyectos. Por otra parte, en este contexto de redefiniciones, la cuestión identitaria estuvo ligada a la lectura realizada sobre el movimiento recientemente desplazado, en efecto, el peronismo fue una pieza clave del discurso antiperonista y el modo en que lo concibieron estuvo lejos de ser homogéneo. Al analizar las formas en que fue abordada la cuestión peronista, Estela Spinelli (2005) complejiza las miradas sobre este actor político que a priori se presentaba como un fenómeno unificado. En su trabajo, la autora logra trazar tres tendencias irreconciliables que se diferencian entre un antiperonismo radicalizado, un antiperonismo optimista y un antiperonismo tolerante ${ }^{21}$.

\footnotetext{
${ }^{21}$ En primer lugar, encontramos un antiperonismo radicalizado, donde agrupa a socialistas, demócratas, demócratas progresistas y democristianos, quienes, por la vía de anulación al peronismo y la redefinición de las reglas del sistema político, pretendieron el perfeccionamiento y la modernización de un orden político liberal que transformara la sociedad. En segundo lugar, el antiperonismo optimista -donde se ubica la UCR del pueblo- caracterizado por la asociación con el gobierno con miras a la construcción de un gobierno populista que prescindiera del autoritarismo propio del peronismo y que respetase las normas republicanas. Por último, el antiperonismo tolerante que, con disensiones internas, incluía un amplio espectro compuesto por el frente frondicista -radicales intransigentes, nacionalistas, comunistas, ex socialistas y ex comunistas-. Este sector se opuso a las reformas políticas y buscó la cooptación del peronismo mediante la incorporación de la experiencia de la
} 
Si nos concentrarnos en la escena política provincial, esta clasificación resulta operativa para interpretar algunos posicionamientos que tomaron los partidos frente al régimen depuesto. Si bien es posible hablar de un consenso general sobre la desperonización, las tres tendencias estuvieron presentes en este espacio, sobre todo, en las expresiones de aquellas fuerzas políticas con alcance nacional. En primer lugar, dentro del antiperonismo considerado tolerante, se ubicaron la UCRI y el PDCP. Con mayor discreción por su escasa llegada a la ciudadanía, aunque con presencia en cargos de gobierno, la UCRP integró el antiperonismo optimista. Por último, con un planteo marcadamente revanchista, el antiperonismo radicalizado se conformó con los demócratas autonomistas, demócratas cristianos y, como expresión netamente local, el Partido Liberal. El discurso del PDA fue contundente en este sentido, cuando en el marco de la creación de una junta reorganizadora publicó una solicitada donde declaró que:

El Partido Demócrata es la gran fuerza conservatista y liberal argentina. Ese es su lema y su sentido. (...) El Partido Demócrata por su esencia conservadora, es contrario a la demagogia. El demagogo agitador de bajas pasiones subyacentes en las sociedades no tiene cabida en sus filas, porque el conservador cuida lo construido en lo moral, lo político, lo social, lo económico y quiere edificar aún más (...) El Partido -cuyos hombres lucharon duramente contra la tiranía-, debe necesariamente cumplir su deber de la hora respetando al Gobierno de la Revolución Libertadora. Debe ser leal con las autoridades surgidas del hecho emancipador. No podemos colocarnos contra la Revolución (...) Es contrario al conservadurismo democrático formular absurdos proyectos de treguas, que llevan tras sí escondido el propósito de que los beneficiarios de estas 'treguas' sean hombres disfrazados de 'apolíticos' pero que en realidad pertenecen a grupos reaccionarios multiformes ${ }^{22}$.

Más allá de estas definiciones, que de algún modo delimitan fronteras entre los antiperonismos locales, un segundo elemento parece tornar más porosas esas diferencias, la llegada al electorado peronista. Luego del derrocamiento, la expulsión del líder político, la desperonización y la

planificación y una idea de alianza de clases que este había ensayado. Spinelli (2005).

${ }^{22}$ Solicitada. Partido Demócrata (Distrito Corrientes) Declaración de la Junta Reorganizadora Provincial. EL, 14-9-1956, p. 2. 
posterior proscripción dejaron sin representación partidaria a una parte importante de la población. En este contexto, la acefalía motivó una disputa en la que los partidos provinciales buscaron la cooptación de ese voto, al que intentaron acercarse de diferentes maneras. Así lo demuestra la postura de la UCR, que mediante la recuperación del discurso yrigoyenista pretendió llegar al núcleo duro de este sector, los trabajadores. Ello se observa en al menos tres situaciones que, a su vez, reflejan la conducta mantenida en toda la etapa. La primera se dio en uno de los comunicados emitidos en el marco de la jornada del primero de mayo de 1956, cuando el comité central expresó un ferviente saludo "a todos los trabajadores de la provincia" y ratificó "su decisión inquebrantable de continuar luchando por la dignificación definitiva de los sectores populares"23; un mensaje similar se reiteraría al año siguiente. En la misma línea estuvo la medida tomada frente a un conflicto entre panaderos y patrones en la capital provincial, cuando desde el partido se comunicó el apoyo a los primeros y se planteó la necesidad de mantener las conquistas sociales de los trabajadores ${ }^{24}$.

El tercer momento que completa el panorama, tuvo lugar en agosto de 1956, luego de la autorización del aumento del precio de la carne por parte de la Intervención Federal25. La UCR se opuso y convocó a una manifestación frente al mercado central donde se repartieron volantes que criticaban el aumento. En esa oportunidad, aquellos que participaron del reclamo fueron detenidos por la policía y, tras el hecho, se produjeron fuertes cuestionamientos al gobierno ${ }^{26}$. En un camino similar, el bloque autonomista liderado por Elías Abad pretendió hacer lo propio incluyendo, por un lado, críticas a la Intervención y a la desperonización y, por otro, un discurso favorable a los trabajadores que se hizo visible en el programa que encabezó como candidato a gobernador, donde las referencias al sindicalismo y las propuestas para el bienestar de los obreros fueron reiteradas. Por su parte, el PL también se propuso ocupar el lugar de representación de los sectores populares. En efecto, la campaña de 1958 apuntó a recuperar la calidad de vida de la clase trabajadora, pero con anterioridad a esta, fueron constantes las actividades para el fomento del cooperativismo en los barrios de la Capital. Con motivo de la difusión de un encuentro llevado a cabo en el ámbito rural, el partido se consideraría como

\footnotetext{
${ }^{23}$ Mensaje de la UCR a los trabajadores. EL, 30-4-1956, p. 2.

${ }^{24} E L, 19-6-1956$, p. 2.

${ }^{25} E L, 23-8-1956$, p. 2.

${ }^{26} E L, 27-8-1956$, p. 2.
} 
una fuerza con un programa "insuperable", donde la clase trabajadora tenía "preeminencia en todos sus derechos" 27.

La realidad del recién creado PDC continuó esta tendencia. En numerosas ocasiones, sus dirigentes demandaron con insistencia la constitución de comisiones paritarias, la reorganización de los sindicatos a través de elecciones internas libres y un urgente tratamiento de la cuestión obrera a fin de conseguir la paz social ${ }^{28}$. Se concibieron a sí mismos como representantes del pueblo trabajador y se mostraron preocupados por su situación económica ante el retraso de los salarios en relación con el aumento del costo de vida ${ }^{29}$. Lo mismo puede decirse sobre el problema de la vivienda ${ }^{30}$, el problema agrario ${ }^{31}$-para lo cual plantearon la necesidad de una "reforma agraria integral" que abarcara todos los aspectos de la vida rural- o la posición que adoptaron frente a las cesantías indiscriminadas en la administración pública, motivadas por cuestiones políticas ${ }^{32}$. Respecto a ello, consideraban la privación del trabajo por causas ideológicas como un acto de injusticia inaceptable y llamaron a evitar el revanchismo como parte de la doctrina cristiana ${ }^{33}$. Las variaciones en el discurso y la aparente búsqueda de pacificación en el espacio provincial constituyen posiciones que en ocasiones parecen contradecir las posturas de los partidos políticos del orden nacional. Consideramos que al colocar la atención en experiencias extracéntricas como esta, podemos complejizar algunas conclusiones más generales e interpretar las alianzas, negociaciones y giros discursivos sucedidos en contextos específicos como respuestas a una realidad situada.

${ }^{27} E L, 12-7-1956$, p. 2.

${ }^{28} E L, 1-12-1956$, p. 2.

${ }^{29} E L, 30-4-1956$, p. 2.

${ }^{30} E L, 16-4-1956$, p. 2.

${ }^{31} E L, 9-6-1956$, p. 2.

${ }^{32}$ En este sentido, llevaron a cabo una importante campaña en Corrientes por la reincorporación de los docentes cesanteados sin previo sumario, consiguiendo que se revirtiera la medida. EL, 10-4-1956, p. 2.

${ }^{33} E L, 29-3-1956$, p. 2. 


\section{El "recuento globular" y las elecciones generales (1957-1958)}

Para la agenda del gobierno central, la reforma de la Constitución era un paso insoslayable en el camino de la pacificación y la restauración del orden democrático. Una vez confirmada su realización, se estableció el 28 de julio de 1957 como fecha para elegir a los representantes constituyentes y el anuncio encendió el debate entre los distintos partidos políticos. Las posturas, lejos de ser homogéneas, se expresaron con matices y uno de los puntos polémicos fue el de la propia legitimidad de la convocatoria (Spinelli, 2001). A ese clima político, se sumaba el hecho de que los comicios serían el primer desafío en el que las fuerzas antiperonistas medirían su caudal de votantes. De este modo, con la mirada puesta en el eventual retorno democrático, se abocaron al inicio de las campañas y los meses subsiguientes no estuvieron exentos de disputas.

Los principales focos de conflicto intrapartidario se dieron en dos de los partidos locales, justamente aquellos que venían de atravesar procesos de fraccionamiento. La Unión Cívica Radical, dividida desde fines de 1956 en UCR Intransigente y UCR del Pueblo, contaba en Corrientes con una representación bien diferenciada y mientras los primeros gozaban de una amplia adhesión ciudadana, los segundos conformaron una fuerza minoritaria ${ }^{34}$. Fue precisamente en la UCRI donde los desacuerdos llevarían a la crisis. El principal desencadenante fue que la intransigencia, que llevaría adelante elecciones internas para definir a los candidatos constituyentes, también escogería a sus representantes para las generales en el mismo comicio. La existencia de intereses confrontados se tradujo en la presentación de dos listas, tanto para diputados convencionales como para candidatos a los cargos provinciales ${ }^{35}$. La lista verde, con la fórmula Piragine Niveyro-Félix Gómez para gobernador y vice, se alzó con la victoria el 23 de junio, pero sus opositores de la lista blanca cuestionaron el procedimiento y pidieron la impugnación ${ }^{36}$. Las acusaciones se replicaron desde ambos bandos y derivaron en la intervención por parte del comité nacional que designó a David Blejer -correligionario rosarino- como

\footnotetext{
${ }^{34} \mathrm{En}$ las elecciones para convencionales constituyentes de 1957, la UCRI obtuvo 77.624 votos en el ámbito provincial. Por su parte, la UCRP logró contabilizar solamente 12.897 adhesiones. EL, 30-7-1957, p. 3.

${ }^{35} E L, 23-5-1957$, p. 2.

${ }^{36} E L, 25-6-1957$, p. 1.
} 
delegado para solucionar el conflicto. Ante la urgencia, la junta reorganizadora decidió seleccionar proporcionalmente los candidatos constituyentes de ambas boletas, pero el escrutinio definitivo para los otros cargos se definió recién en octubre ${ }^{37}$. A pesar de que el dictamen consagraba a los verdes, la división en este sector del radicalismo se extendió por todo el territorio provincial hasta apaciguarse recién en diciembre, no sin la previa mediación del propio Frondizi y la presión del nuevo contexto electoral que hacía necesaria la unidad.

En el autonomismo, que ya se encontraba dividido, la crisis partidaria se dilató y contó con varios enfrentamientos. Una de las discusiones iniciales giró en torno al uso del nombre del Partido Demócrata, que el propio Abad continuó utilizando aun después de la fragmentación. Este cruce se desarrollaría por unos meses hasta que la justicia electoral reconoció a la junta reorganizadora nacional -liderada por Basavilbaso- como autoridad legítima del PDN y, si bien también reconoció a la línea disidente, la obligó a utilizar una denominación diferente, conformándose así el nuevo Partido Demócrata Conservador Popular (PDCP) ${ }^{38}$. El segundo momento se dio en el marco de las elecciones constituyentes, donde el PDA y el PDCP enviaron listas propias. La discusión que se inició en plena campaña e intentó ser capitalizada por ambos sectores, tuvo lugar luego de la publicación de diversas denuncias y declaraciones en la prensa local vinculadas a la boleta del conservadorismo popular. El hecho de haber incluido una fotografía de Juan Ramón Vidal -referente indiscutido del autonomismo- implicó el reclamo de Diomedes Rojas, quien aseguraba que la misma violaba las normativas establecidas y que con esa maniobra, se pretendía manipular y confundir el voto del elector autonomista analfabeto ${ }^{39}$. Por su parte, Abad acusó a sus adversarios políticos de intentar negar la herencia y el legado de la figura de Vidal en el movimiento. A pesar de las disputas, los resultados de los comicios fueron contundentes y el electorado autonomista se volcó al partido dirigido por Abad, que alcanzó a obtener dos diputados.

El Partido Liberal y el Demócrata Cristiano fueron los menos afectados por los roces internos, aunque en el caso del liberalismo fue evidente la existencia de una juventud organizada que planteó críticas a los dirigentes

${ }^{37} E L$, 26-10-1957, p. 2.

${ }^{38} E L$, 5-12-1956, p. 2.

${ }^{39} E L, 8-7-1957$, p. 2 y 6.

RHAA v.56 n.1, 2021. ISSN: 0556-5960, ISSNe 2314-1549. CC BY-NC-SA 4.0 
de mayor experiencia. Este sector, agrupado en la Juventud Liberal dirigida por Ricardo Leconte, estuvo comprometido en la reorganización partidaria y en la campaña electoral previa a la reforma, espacios desde donde fue ganando protagonismo. Si bien la prensa refleja la existencia de cierto clima de época caracterizado por el enfrentamiento generacional, que contribuye a entender estas diferencias ${ }^{40}$, el tono de la confrontación que tuvo lugar durante la convención constituyente fue tal que desencadenó una crisis partidaria. El conflicto se inició por la adhesión de los representantes liberales al denominado "bloque del centro", conformado por otros partidos provinciales, lo que motivó la protesta por una decisión "sin consulta previa" que afectaba a la independencia partidaria. La posterior falta de acuerdo en las reuniones entre el presidente Mariano Gómez y Leconte, determinó el alejamiento temporal de este y otros cuadros juveniles ${ }^{41}$.

En esta segunda etapa, a su vez, los vínculos entre las fuerzas políticas y la Intervención se resquebrajaron frente a la competencia electoral cada vez más próxima. A la ya mencionada confrontación entre el PDCP y el interventor Bianchi, se sumó otra. En marzo de 1957, la UCRA, encabezada por Pedro Numa Soto, resolvió el alejamiento de todo el bloque partidario de la Junta Consultiva y publicó un documento argumentando que la decisión fue tomada por la falta de prescindencia política del gobierno, al cual denunciaron por actuar en beneficio de la UCRI y del PL ${ }^{42}$. El hecho repercutió de tal manera que provocó, por un lado, sucesivas respuestas por parte los distintos sectores partidarios implicados, que intentaron desprenderse de las acusaciones ${ }^{43}$. En ellas, el factor de poder electoral volvía a centrarse en la distribución de cargos policiales. Por otra parte, también obligó a Bianchi a intentar aclarar la situación frente a las autoridades nacionales. En una comunicación con el vicepresidente, señaló que los dirigentes del antipersonalismo habían exigido reemplazos en cargos de la policía (para ubicar a los suyos) bajo la amenaza de que retirarían a sus representantes consultivos de no cumplirse lo solicitado ${ }^{44}$.

${ }^{40} E L, 20-2-1957$, p. 2.

${ }^{41} E L, 13-9-1957$, P. 2 y entrevista realizada a Ricardo Leconte.

${ }^{42} E L, 13-3-1957$, p. 2.

${ }^{43} E L, 16-3-1957$, p. 2.

${ }^{44}$ Archivo Histórico del Departamento de Estudios Históricos Navales (DEHN), Fondo Isaac Francisco Rojas (FIFR), Fondo Documental, Caja 12, Correspondencia personal, Carta del Interventor Bianchi al Vicepresidente Isaac Rojas. Buenos Aires, 16-3-1957. 
La situación concluyó con la negativa del interventor y la posterior destitución de los miembros de la Junta.

Más allá de las disputas, las elecciones que definieron a los siete convencionales que correspondían a Corrientes se llevaron a cabo sin mayores contratiempos ${ }^{45}$. El triunfo fue contundente para los radicales intransigentes, que obtuvieron tres bancas, ocupadas por Blas Benjamín de la Vega, Luis Maciel y Víctor Hugo Fleitas. En segundo lugar, se ubicó el Partido Liberal, con dos representantes, Mariano Gómez y Ernesto Meabe y, por último, el Partido Demócrata Conservador Popular, con otros dos convencionales, Elías Abad y Evaristo López. Más tarde, Abad renunciaría a su banca y sería reemplazado por Pedro Obregón.

Los resultados de los comicios otorgaron claridad al panorama electoral local (ver cuadro no 3). De esta manera, la UCRI se consagraba como primera mayoría y con aspiraciones reales de cara a la competencia por la gobernación. No obstante, también consolidaba a dos fuerzas tradicionales que ya habían establecido alianzas para gobernar la provincia, el PL y el PDCP. Otro elemento a tener presente fue la "escasa" cantidad de votos en blanco que, a diferencia de provincias como Santa Fe, donde superó por más de 100 mil votos a la primera fuerza o Buenos Aires, donde alcanzó el segundo lugar, sólo contabilizó un 10,5\% del total de sufragios y terminó en cuarto lugar ${ }^{46}$. El voto en blanco, como expresión vinculada directamente al elector peronista, fue seriamente estudiado en todos los distritos por las autoridades del gobierno, sobre todo, de cara al retorno democrático. Un análisis del Ministerio del Interior expresa que en Corrientes "la masa peronista ha vuelto a su cauce de origen" y añade que los seguidores del ex gobernador peronista Filomeno Velazco, apoyaron al PL. A su vez, los que acompañaban a Raúl Castillo, se fueron hacia el conservadorismo popular de Elías Abad y hacia el radicalismo frondizista ${ }^{47}$. Con estos elementos, se abría un trayecto hacia las generales que, por un lado, ponía de manifiesto la necesidad de una intensa campaña para captar la mayor cantidad de votos y, por el otro, obligaba a las negociaciones interpartidarias para alcanzar el triunfo.

\footnotetext{
${ }^{45} E L, 3-8-27$, p. 1.

${ }^{46}$ DEHN, FIFR, Caja 32, Informes sobre la situación Nacional (1956-1958), Informe del Ministerio del Interior. Buenos Aires.

${ }^{47}$ DEHN, FIFR, Caja 32, Informes sobre la situación Nacional (1956-1958), Informe del Ministerio del Interior. Buenos Aires.
} 
Cuadro $n^{\circ}$ 3: Resultados totales de elección de diputados constituyentes.

Provincia de Corrientes, 1957

\begin{tabular}{|l|c|c|c|}
\hline \multicolumn{5}{|c|}{ RESULTADOS TOTALES DE ElECCIÓN DE DIPUTADOS CONSTITUYENTES } \\
PROV INCIA DE CORRIENTES (1957) \\
\hline Partido Político & Cantidad de Votos & $\%$ & Diputados Electos \\
\hline UCRI & 77.624 & $33,9 \%$ & 3 \\
\hline PL & 48.101 & $21 \%$ & 2 \\
\hline PDCP & 40.222 & $17,6 \%$ & 2 \\
\hline PDC & 14.762 & $6,5 \%$ & - \\
\hline UCRP & 12.897 & $5,6 \%$ & - \\
\hline PDA & 7.680 & $3,4 \%$ & - \\
\hline PDP & 2.108 & $0,9 \%$ & - \\
\hline PC & 1.302 & $0,6 \%$ & - \\
\hline Votos en Blanco & 24.132 & $10,5 \%$ & - \\
\hline
\end{tabular}

Fuente: Elaboración propia a partir de La Mañana, 22-3-58, p. 5 (AGPC).

\section{La Convención Constituyente: los debates en torno al orden político}

El anuncio sobre la reforma constitucional actuó como catalizador de un debate que recorrió, al menos en la política provincial, tres tópicos sobre los cuales los partidos manifestaron su posicionamiento. El primer punto -quizá el único en el que coincidieron todas las fuerzas antiperonistas- estuvo relacionado con las medidas a tomar frente a la Constitución de 1949. En este sentido, el rechazo generalizado tuvo un lugar de encuentro en el apoyo a la derogación de la carta magna modificada bajo el peronismo. Además, debido a que el retorno a la Constitución de 1853 generaba la necesidad de una actualización, el consenso en los distintos sectores se extendió sobre esta cuestión, expresándose en muchos casos el carácter ineludible de una reforma tanto en el orden nacional como en el ámbito provincial.

Ahora bien, las posiciones encontradas se develaron en el segundo y tercer punto. Por un lado, la discusión se planteaba en torno a cuándo debía llevarse a cabo la reunión constituyente -y bajo qué tipo de gobierno- y, por el otro, sobre la necesidad de una reforma del orden político. El primer asunto puso en cuestionamiento la legitimidad misma de la convocatoria, 
realizada en el marco de un gobierno que no había accedido al poder mediante el voto popular y que había excluido del juego electoral a la fuerza política con mayores bases de apoyo. El segundo, por su parte, abrió el debate sobre la noción misma de democracia al incorporar el sistema de representación proporcional (Spinelli, 2001). Ambas cuestiones definieron dos grandes posturas detrás de las que se agruparon los distintos partidos locales. En la línea de aquellos que se manifestaron en contra del llamamiento y expresaron críticas a la gestión provisional, se encontraban la UCRI y el PDCP. El radicalismo frondizista, en sintonía con el comité nacional, fue riguroso y planteó el riesgo existente de generar un documento ajeno a los intereses del pueblo. En efecto, las declaraciones de campaña del dirigente intransigente, Patricio Vargas Gómez, fueron contundentes:

(...) las medidas de este gobierno no han pacificado la nación, ni han superado la crisis moral, ni su quebrantamiento económico, ni tampoco recuperado ante el mundo el prestigio de la República (...) por ello se resiste (el pueblo) a aceptar como valedera una reforma Constituyente de la que amenaza surgir una Carta Magna que traicione su destino ${ }^{48}$.

Los argumentos de la UCRI, además, incluían un rotundo rechazo a la reforma del orden político. En relación con ello, esgrimieron que la representación proporcional buscaba otorgar una mayoría ficticia a fuerzas minoritarias carentes de un caudal de votos significativo, algo que para su interpretación iba "en contra de los intereses nacionales y populares". A pesar de haber quedado como segunda mayoría en la convención -detrás de la UCRP-, a finales de agosto los diputados intransigentes no tardaron en retirarse de sus bancas y llamaron a la impugnación de la asamblea. En una postura bastante cercana, el PDCP resolvió asistir a los comicios, aunque planteó la finalidad de participar en la reunión para "oponerse a toda reforma constitucional y sostener la vigencia de la Constitución sancionada en 1853 con sus reformas posteriores, excepto la de 1949"49. De esta forma, el conservadorismo popular presentaba algunos matices a la vez que consideraba que no estaban dadas las condiciones para un hecho de tal magnitud y sostenía que la convocatoria debería surgir de un órgano representativo del pueblo, como el Congreso, una vez alcanzada la

\footnotetext{
${ }^{48}$ Reportaje de LT7 al Señor Patricio Vargas Gómez. EL, 25-7-1957, p. 2.

${ }^{49}$ Partido Demócrata Autonomista (Conservador Popular). Sesionó la junta de gobierno. EL, 25-6-1957, p. 2.
} 
normalización institucional. Hacia el mes de septiembre, iniciadas las sesiones constituyentes, desde el partido se expresaron que:

(...) la reunión en Santa Fe no podrá crear nada duradero porque sólo representa a una parte del país y porque no ha encontrado eco alguno en los millones de hogares que aspiran a la paz por el camino del entendimiento y no de la imposición ${ }^{50}$.

En el otro extremo, con posiciones de apoyo tanto para la convocatoria como para la reforma política, se hallaban el PDA, el PL y el PDC. En una línea leal al gobierno, el autonomismo de Diomedes Rojas consideró necesaria la modificación de la carta de 1853 y se pronunció a favor del sistema de representación proporcional, aceptado ya en la convención nacional que el partido había tenido en junio de 1957. Además de ello, manifestó de forma explícita su adhesión al programa de la Revolución Libertadora. Una posición similar fue adoptada por los demócratas cristianos, que promovieron un necesario perfeccionamiento de la democracia política, capaz de dotarla de un sentido popular y cristiano propio del "ser nacional", y por los liberales, cuyo presidente, Mariano Gómez, explicitó:

Sostenemos el derecho que el Gobierno convoque a elecciones para reformar la Constitución de 1853, por cuanto somos honestos y sinceros y sí, como todos los demás partidos políticos hemos apoyado al Gobierno en la derogación de la Constitución de 1949, por considerar que esta daba excesivos poderes al Presidente de la República y anulaba casi totalmente la esencia federalista, como no hemos de ser ahora también sinceros y honestos en reconocer que el Gobierno Provisional está facultado a convocar a la Reforma, si lo apoyamos en un acto que era sin intervención del pueblo lo debemos apoyar ahora a este otro que no es nada más ni nada menos que una convocatoria para que el pueblo se dé la constitución que más convenga a sus intereses ${ }^{51}$.

La Constitución provincial también fue motivo de análisis, sin embargo, los posicionamientos en este aspecto presentaron algunas variantes con los discursos emanados anteriormente en el marco nacional, sobre todo, en cuanto al régimen de representación proporcional. Así lo demuestra una

50Politimascope. EL, 19-9-1957, p. 8.

${ }^{51}$ Reuniones del Partido Liberal. EL, 25-6-1957, p. 2. 
situación ocurrida en el contexto de la reforma de una ley electoral de 1915, donde se establecía dicha modalidad. En el caso mencionado, los cambios impulsados en la legislación -que estaría vigente para los próximos comicios- planteaban solamente una reconfiguración de las secciones electorales, buscando así equilibrar la representación de las circunscripciones en función de la cantidad de habitantes ${ }^{52}$. Sin embargo, más allá de estas modificaciones, se mantenía el sistema proporcional establecido en la carta provincial de 1913. El proyecto fue apoyado unánimemente por todo el arco antiperonista e incluyó a los radicales intransigentes y a los conservadores populares. Como consecuencia, el interventor dictó un decreto con el que encomendó a la Fiscalía de Estado la preparación de la nueva norma legal ${ }^{53}$ la cual, con el aval de los partidos, se puso en funcionamiento para diciembre de $1957^{54}$.

\section{La carrera hacia los comicios generales en la provincia}

El clima político previo a la normalización, con las elecciones generales proyectadas para el 23 de febrero de 1958, estuvo atravesado en la contienda nacional, por la disputa entre los dos radicalismos que se perfilaban como los grandes aspirantes a la presidencia. Con el apoyo explícito del gobierno y confiados luego de la victoria en los comicios constituyentes de julio, la UCRP llevó como candidatos a la fórmula Ricardo Balbín-Santiago del Castillo. Los radicales del pueblo se presentaron a sí mismos como "la garantía moral de la democracia" y recuperaron el discurso de la tradición partidaria que concebía al movimiento como "religión cívica", a la vez que mezclaba la causa radical con la de la nación. Asimismo, el ataque a la línea intransigente fue una constate que se enfocó en señalar la alianza de estos con el totalitarismo (Spinelli, 2005). Por su parte, la UCRI de Arturo Frondizi y Alejandro Gómez, profundizó la estrategia de oposición a la Revolución, al tiempo que viró en un paulatino acercamiento al peronismo, consolidado luego en el "pacto" con Perón, pero que venía materializándose en las múltiples críticas a la desperonización, los reclamos por los ex funcionarios detenidos y las propuestas de campaña

\footnotetext{
${ }^{52}$ La ley de 1915 venía siendo cuestionada desde hacía décadas por el desequilibrio que se había planteado entre las secciones electorales. Véase: Solís Carnicer (2019).

${ }^{53}$ AGPC, SG, 1957, Decreto 3925/23.

${ }^{54} E L, 20-12-1957$, p. 1.
} 
condensadas en el lema "paz y bienestar para veinte millones de argentinos" (Spinelli, 2005).

Paralelamente, el escenario local estuvo acaparado por las campañas provinciales por la gobernación, los cargos legislativos y municipales, que se disputarían en la misma fecha. Si tenemos en cuenta el resultado del "recuento globular" de julio, la UCRI, con la fórmula Piragine Niveyro-Félix Gómez, el Partido Liberal, con Mariano Gómez-Díaz Colodrero, y el PDCP, con Elías Abad-Pedro Obregón constituían las principales fuerzas. La actividad política fue intensa y comprendió actos multitudinarios, giras proselitistas y la difusión de los programas de gobierno. En este sentido, el radicalismo frondizista trazó el objetivo de "terminar con los antagonismos que dividían a la sociedad argentina", algo que complementaba los lineamientos del partido a nivel nacional. En el PL se apeló a valores identitarios locales, realzando su figura como auténtica expresión de la correntinidad y como verdadera alternativa al radicalismo imperante. Buscó llegar a sectores amplios y diversos, entre ellos, a trabajadores, productores y empresarios, para lo cual combinó propuestas de industrialización con proyectos de redistribución del latifundio y organización de cooperativas en el mundo del agro55. El tercer actor, el conservadurismo popular, llevó adelante un "programa de veinte puntos" en el cual se daba un espacio privilegiado al concepto de "libertad" como base del derecho político, al sindicalismo y la defensa de los derechos sociales consagrados ${ }^{56}$. Las múltiples reuniones de campaña fueron concebidas como muestra del fervor popular del partido y en ellas predominó un discurso que apuntaba a la pacificación nacional y "la unión de la familia argentina"57.

En lo que respecta a la definición presidencial, la UCRI se impuso de manera contundente (ver cuadro no 4). Fue seguida por el PL, que con sus propios candidatos obtuvo un total de cinco electores, e inmediatamente detrás, se ubicó el PDCP. Si consideramos el comportamiento del voto en blanco respecto de las constituyentes, no se observan cambios significativos, por lo que podemos interpretar que el pacto con Perón no fue decisivo en el territorio provincial. Un análisis más general, a su vez, muestra una estabilidad del electorado en la mayoría de las fuerzas políticas.

${ }^{55} E L, 22-1-1958$, p. 2.

${ }^{56} E L, 2-1-1958$, p. 3.

${ }^{57}$ LM, 8-2-1958, p. 4. 
Las elecciones generales provinciales mantienen una correlación con lo anterior (ver cuadro $\mathrm{n}^{\circ}$ 5). Los resultados del escrutinio definitivo fueron publicados a principios de marzo y consagraron a la fórmula intransigente de Piragine y Gómez. No obstante, el triunfo en las urnas no fue suficiente para alcanzar los votos necesarios en el colegio electoral por lo que el escenario todavía debía resolverse. Las especulaciones y los intentos de acuerdo empezaron de manera inmediata y en la prensa se consideraba la posibilidad de una nueva alianza entre liberales y autonomistas -coalición electoral y de gobierno que ya había gobernado la provincia y que incluso había nacido como respuesta a la emergencia radical décadas atrás-. Sin embargo, contra los pronósticos periodísticos, las negociaciones interpartidarias culminaron con el apoyo de Elías Abad y su bloque de electores a la fórmula radical, definiendo la contienda en favor de la UCRI.

Cuadro $n^{\circ}$ 4: Resultados totales de elección de presidente y vice. Provincia de Corrientes, 1958

\begin{tabular}{|c|c|c|}
\hline \multicolumn{3}{|c|}{$\begin{array}{c}\text { RESULTADOS TOTALES DE ELECCIÓN DE PRESIDENTE Y VICE } \\
\text { PROVINCIA DE CORRIENTES (1958) }\end{array}$} \\
\hline Partido Político & Cantidad de Votos & Cantidad de Electores \\
\hline UCRI & 81.175 & 11 \\
\hline PL & 38.922 & 5 \\
\hline PDCP & 35.029 & - \\
\hline UCRP & 20.376 & - \\
\hline PDC & 11.449 & - \\
\hline PDA & 2.527 & - \\
\hline Otros & 12.511 & - \\
\hline Votos en Blanco & 21.092 & - \\
\hline
\end{tabular}

Fuente: Elaboración propia a partir de La Mañana (AGPC). 
Cuadro $\mathrm{n}^{\circ}$ 5: Resultados totales de elección de gobernador y vice.

Provincia de Corrientes, 1958

\begin{tabular}{|l|c|c|}
\hline \multicolumn{3}{|c|}{$\begin{array}{c}\text { RESULTADOS TOTALES DE ELECCIÓN DE GOBERNADOR Y VICE } \\
\text { PROV INCIA DE CORRIENTES (1958) }\end{array}$} \\
\hline \multicolumn{1}{|c|}{ Partido Político } & Cantidad de Votos & Cantidad de Electores \\
\hline UCRI & 85.773 & 10 \\
\hline PL & 51.114 & 8 \\
\hline PDCP & 38.004 & 5 \\
\hline UCRP & 20.091 & 2 \\
\hline PDC & 11.705 & 2 \\
\hline PDA & 4.478 & - \\
\hline Otros & 9.861 & - \\
\hline Votos en Blanco & 22.113 & - \\
\hline
\end{tabular}

Fuente: Elaboración propia a partir de La Mañana y El Liberal (AGPC).

\section{Conclusiones}

Durante el gobierno de la autodenominada Revolución Libertadora los partidos políticos antiperonistas que actuaron en la provincia de Corrientes tuvieron un marcado protagonismo. Esto se evidenció en la adhesión al golpe, en el retorno de las fuerzas a la actividad política y, sobre todo, en la participación en el gobierno mediante la ocupación de cargos en la administración pública, las comisiones investigadoras y la junta consultiva, así como en las constantes negociaciones con las autoridades. En este marco, se originó una importante movilización hacia el interior de cada una de las fuerzas, que derivó en procesos de reorganización y, en algunos casos, fraccionamientos que implicaron el surgimiento de nuevos partidos.

En el escenario abierto tras el golpe existieron dos elementos clave que signaron la etapa y dieron lugar a conflictos intra y extrapartidarios: las posturas asumidas frente a la desperonización -y la cuestión peronista- y ante el replanteo del orden político. En ocasiones, los debates reprodujeron tópicos de alcance nacional y en otras predominó una lógica partidaria local. En lo que respecta a la primera, teniendo en cuenta esta dicotomía local/nacional, la posición que adoptó cada partido fue diferenciada. Si bien todos coincidieron en criticar al peronismo, algunos sectores -como el 
PDA- se mostraron más revanchistas y otros cuestionaron directamente la política desperonizadora, como la UCRI y el PDCP. Al mismo tiempo, es evidente que todo el arco político buscó ocupar el espacio que el peronismo había dejado en la representación de los trabajadores, mediante la incorporación de elementos vinculados a la defensa de este sector -en sus discursos y programas- que no siempre habían formado parte de sus principios en etapas previas.

Respecto al orden político, debemos señalar que la agenda se dividió en dos discusiones. Uno de los temas fue la reforma constitucional y el sistema de representación a incluir en ella, el otro, se concentró en la modificación de la Ley Electoral de 1915 que regiría para los comicios provinciales. En cuanto a la primera discusión, la UCR y el PDCP cuestionaron la legitimidad de la convención constituyente y fueron claros defensores del sistema de lista incompleta consagrado en la Ley Sáenz Peña. En otro extremo, el PL, PDC y PDA apoyaron la reforma e impulsaron la implementación de la representación proporcional. Sobre la Ley de 1915, a diferencia de las posturas anteriores, existió consenso en todos los partidos y se abogó por el mantenimiento del sistema proporcional -vigente en la provincia desde 1889- que establecía esa legislación, inclusive desde el radicalismo y el conservadurismo popular. Este criterio unificado se mantuvo a la hora de reformar el orden político provincial en lo relativo a la división de las secciones electorales. Al analizar estos posicionamientos desde una perspectiva regional, identificamos algunas rupturas con las líneas adoptadas por los partidos de alcance nacional. Consideramos que ello responde a las necesidades propias del contexto político y a las estrategias adoptadas en consecuencia por las dirigencias.

En lo referido a las crisis intrapartidarias, la división del PDA también debe entenderse a la luz de los antecedentes locales, pues más allá de la fractura determinada por lo sucedido en el partido a nivel nacional -donde la mirada sobre el peronismo fue central-, queda claro que la misma recuperó diferencias entre los sectores encabezados por Elías Abad y Diomedes Rojas, que se remontaban a la década de 1940. En la UCR, la ruptura entre frondizistas y los que convergerían en el radicalismo del pueblo, respondió a una crisis de alcance nacional. Sin embargo, la mayoría abrumadora de la línea intransigente impidió que se replicara en la provincia el papel que la UCRP tuvo en el país. Aquí la competencia se dio al interior de la UCRI, donde los intereses contrapuestos llevaron a disputas por las candidaturas y los conflictos generados a partir de estas se tradujeron en la intervención 
del comité durante gran parte del período. Si bien en el PL no se llegó al fraccionamiento, también existieron diferencias internas con tintes generacionales. No obstante, lo característico de este partido fue que luego de años de abstención electoral durante el peronismo, práctica que lo había transformado en una especie de aliado tácito de esta fuerza, vio resurgir sus posibilidades ante el retorno de un considerable caudal de electores luego de la proscripción, sobre todo aquellos que se habían alineado detrás del ex gobernador peronista Filomeno Velazco. Estas idas y vueltas en el liberalismo -que también sucedieron entre autonomistas y los peronistas de Castillo- revelan las complejidades que operaron en este escenario en el marco de la desperonización.

Un tercer elemento de la dinámica política fue la constante puja por los espacios de poder, que no solamente propició confrontaciones al interior y entre partidos, sino que también originó tensiones con la Intervención Federal. Las acusaciones hacia el gobierno por favoritismo y falta de prescindencia política fueron parte de una realidad en la cual las distintas fuerzas buscaron ejercer presión para obtener cargos y, desde allí, disputar con ventaja ante el inminente retorno democrático. En estos pleitos, fue predominante la discusión en torno a los puestos jerárquicos en la policía provincial, considerados un factor determinante a nivel electoral, pero también estuvieron presentes las críticas a la gestión. Estos conflictos, como es lógico, tuvieron repercusiones en la configuración del escenario político.

El abordaje de la experiencia de los partidos antiperonistas permitió aproximarnos al clima político imperante y recuperar al espacio provincial en su dimensión política productiva donde las reconfiguraciones partidarias, las disputas y la búsqueda de equilibrio en el nuevo escenario, los encontró en un constante tránsito entre la valorización de la democracia y la connivencia con la dictadura. El proceso no se dio sin matices y las diferentes posiciones asumidas por -y en- los partidos políticos de Corrientes no fueron estáticas ni homogéneas. 


\section{Bibliografía}

Ansaldi, W. (2014). De la Vox populi, Vox Deus, a la Vox populi, Vox Mercatus. La cuestión de la democracia y la democracia en cuestión. Estudios, (31), pp. 13-31. https://doi.org/10.31050/1852.1568.n31

Álvarez, Y. (2016). Aportes para una historia de la Revolución Libertadora en Mendoza. Páginas, 8 (16), pp. 7-24. https://doi.org/10.35305/rp.v8i16.208

Castillo, F. (2016a). Presentación dossier. Páginas, 8 (16), pp. 3-6. https://doi.org/10.35305/rp.v8i16.207

Castillo, F. (2016b). La represión antiperonista y su justificación en Jujuy en tiempos de la Revolución Libertadora. Páginas, 8 (16), pp. 82-98. https://doi.org/10.35305/rp.v8i16.212

Cavarozzi, M. (1983). Autoritarismo y Democracia 1955-1983. C.E.A.L.

Ferreyra, S. (2016). Junta Consultiva y Comisiones Investigadoras en la Provincia de Buenos Aires: usos de la escala para pensar el conflicto peronismo-antiperonismo. Páginas, 8 (16), pp. 44-60. https://doi.org/10.35305/rp.v8i16.210

Ferreyra, S. (2018). El peronismo denunciado. Antiperonismo, corrupción y comisiones investigadoras durante el golpe de 1955. Eudem-GEU.

Lichtmajer, L. (2016). ¿Una crisis de crecimiento? La expansión de la Unión Cívica Radical de Tucumán durante la "Revolución Libertadora". Páginas, 8 (16), pp. 25-43. https://doi.org/10.35305/rp.v8i16.209

Melón Pirro, J. C. (2009). El peronismo después del peronismo. Resistencia, sindicalismo y política luego del 55. Siglo XXI.

Nun, J. (1973). El control obrero y el problema de la organización. Pasado y Presente, (2-3), 205-232.

O’Donnell, G. (1972). Modernización y autoritarismo. Paidós.

Persello, A. V. (2007). Historia del radicalismo. Edhasa.

Portantiero, J. C. (1973). Clases dominantes y crisis política en la Argentina. En O. Braun (Ed.). El capitalismo argentino en crisis (pp.73-118). Siglo XXI.

Ruffini, M. (2016a). Tiempos antiperonistas en la Patagonia argentina. La acción de las Comisiones Investigadoras durante la "Revolución 
Libertadora".

Páginas,

8 https://doi.org/10.35305/rp.v8i16.211

(16),

pp.

61-81.

Ruffini, M. (2016b). Dictadura, dirigencia política y sociedad civil. La persecución al peronismo en la Patagonia Argentina durante la "Revolución Libertadora" (1955-1958). Iberoamérica Social, 1, pp. 89107.

Recuperado de http://iberoamericasocial.com/ojs/index.php/IS/article/view/279

Smulovitz, C. (1991). En búsqueda de la formula perdida: Argentina 19551956. Desarrollo Económico, 31 (121), pp. 113-124. https://doi.org/10.2307/3466730

Solís Carnicer, M. M. (2017). La "Revolución Libertadora" en la provincia de Corrientes. Los partidos políticos, la Iglesia y el Ejército frente al golpe de 1955. Quinto Sol. Revista de Historia, 21 (3), pp. 1-27. http://dx.doi.org/10.19137/qs.v21i3.1129

Solís Carnicer, M. M. (2019). Las paradojas de la política en tiempos de reforma. Partidos, elecciones y prácticas políticas en Corrientes (1909- 1930). ConTexto Libros.

Spinelli, M. E. (2001). El debate sobre el orden político durante los primeros gobiernos antiperonistas, 1955-1958. Anuario del IEHS, 16, pp. 1337. Recuperado de: http://anuarioiehs.unicen.edu.ar/2001.html

Spinelli, M. E. (2005). Los vencedores vencidos. El antiperonismo y la "revolución libertadora". Biblos.

Tcach, C. (1994). Partidos y pactos políticos en la Córdoba Libertadora (1955-1958). Estudios, (3), pp. 17-30. Recuperado de: https://revistas.unc.edu.ar/index.php/restudios/article/view/399

Tcach, C. (2012). De la Revolución Libertadora al Cordobazo. Córdoba, el rostro anticipado del país. Siglo XXI.

Valobra, A. (2013). Derechos políticos femeninos en la Junta Consultiva Nacional. Estudios Sociales, 45 (1), pp. 167-201. https://doi.org/10.14409/es.v45i1.4456 